\title{
Effects of grid size and aggregation on regional scale landuse scenario calculations using SVAT schemes
}

\author{
H. Bormann \\ University of Oldenburg, Department of Biology and Environmental Sciences, Germany \\ Received: 23 January 2006 - Revised: 22 May 2006 - Accepted: 3 July 2006 - Published: 26 September 2006
}

\begin{abstract}
This paper analyses the effect of spatial input data resolution on the simulated effects of regional scale landuse scenarios using the TOPLATS model. A data set of $25 \mathrm{~m}$ resolution of the central German Dill catchment $\left(693 \mathrm{~km}^{2}\right)$ and three different landuse scenarios are used for the investigation. Landuse scenarios in this study are field size scenarios, and depending on a specific target field size ( $0.5 \mathrm{ha}, 1.5 \mathrm{ha}$ and 5.0 ha) landuse is determined by optimising economic outcome of agricultural used areas and forest. After an aggregation of digital elevation model, soil map, current landuse and landuse scenarios to $50 \mathrm{~m}, 75 \mathrm{~m}, 100 \mathrm{~m}, 150 \mathrm{~m}, 200 \mathrm{~m}$, $300 \mathrm{~m}, 500 \mathrm{~m}, 1 \mathrm{~km}$ and $2 \mathrm{~km}$, water balances and water flow components for a 20 years time period are calculated for the entire Dill catchment as well as for 3 subcatchments without any recalibration. Additionally water balances based on the three landuse scenarios as well as changes between current conditions and scenarios are calculated. The study reveals that both model performance measures (for current landuse) as well as water balances (for current landuse and landuse scenarios) almost remain constant for most of the aggregation steps for all investigated catchments. Small deviations are detected at the resolution of $50 \mathrm{~m}$ to $500 \mathrm{~m}$, while significant differences occur at the resolution of $1 \mathrm{~km}$ and $2 \mathrm{~km}$ which can be explained by changes in the statistics of the input data. Calculating the scenario effects based on increasing grid sizes yields similar results. However, the change effects react more sensitive to data aggregation than simple water balance calculations. Increasing deviations between simulations based on small grid sizes and simulations using grid sizes of $300 \mathrm{~m}$ and more are observed. Summarizing, this study indicates that an aggregation of input data for the calculation of regional water balances using TOPLATS type models does not lead to significant errors up to a resolution of $500 \mathrm{~m}$. Focusing on scenario effects the model is more
\end{abstract}

Correspondence to: H. Bormann

(helge.bormann@uni-oldenburg.de) sensitive to input data aggregation as aggregation effects of current data and scenarios partly sum up. The maximum reasonable grid size for scenario calculations decreases to 200 $300 \mathrm{~m}$.

\section{Introduction}

The prediction of water fluxes in changing environments and under changing boundary conditions requires the use of distributed and process-based models which have been validated for different environmental conditions (e.g. climate, topography). Spatially distributed modelling of regional water fluxes and water balances, again, requires different spatial data sets representing the landscape structure. At least information on topography, soils and vegetation is needed. Thereby the higher the resolution of these data is, the better the landscape is represented by the data base (Kuo et al., 1999). Spatial patterns can be represented in more detail and small scale fluxes can be considered by the models. As climate change and environmental change are global problems, predictions are needed in many regions of the world with differing data availability in both resolution and quality. A few studies have examined the effect of grid size of input data on catchment hydrological simulations such as Kuo et al. (1999, focusing on topography), Farajalla and Vieux (1995, soils) and Pelgrum (2000, vegetation). Thus, although it is well documented in the literature that data resolution can have a significant impact on simulation results, there are only a few integrative studies analysing all relevant data sets together (Bormann, 2006; Kuo et al., 1999), and obtained model results often are compared and evaluated without taking data resolution into account. With respect to scenario analysis no studies were found analysing the effect of data resolution on scenario results. Therefore, this study elaborates in detail which effect data and model resolution can have on simulated water balances and scenario effects. Based on a detailed

Published by Copernicus GmbH on behalf of the European Geosciences Union. 


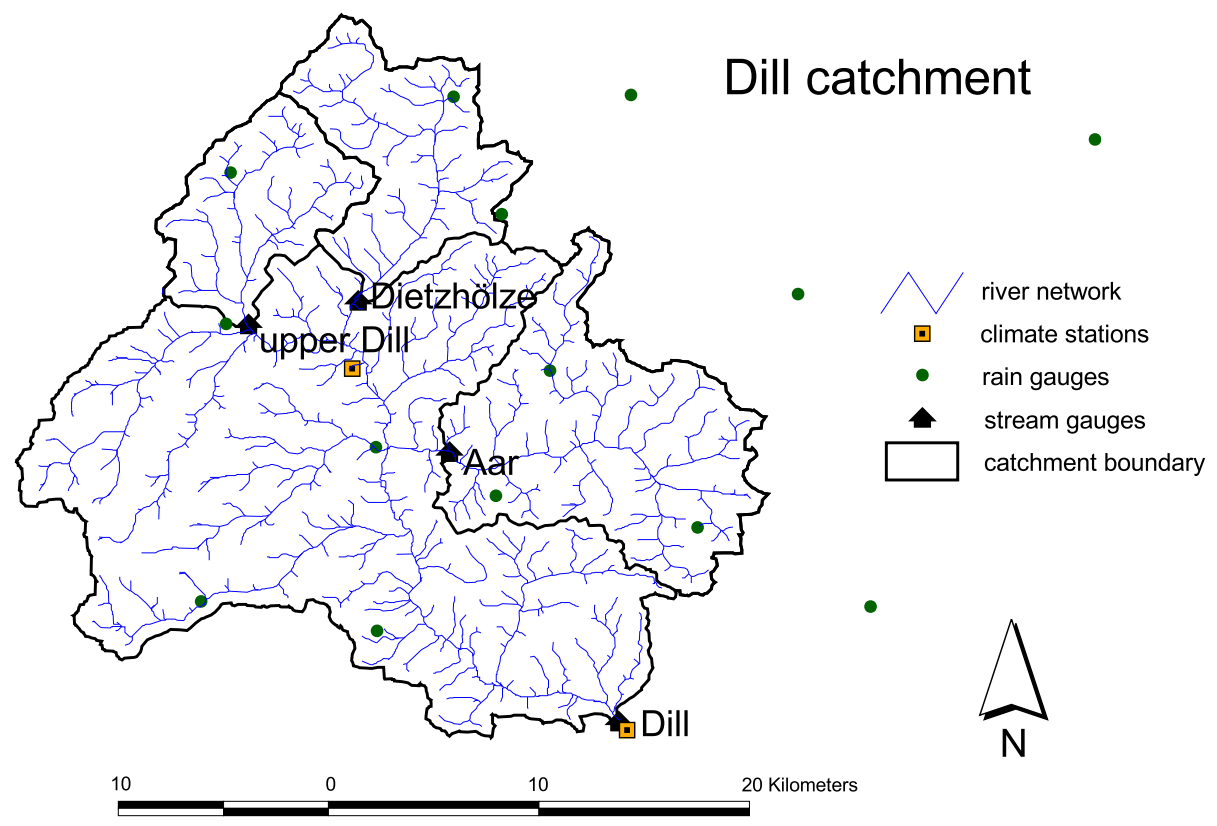

Fig. 1. Subcatchments (upper Dill, Dietzhölze, Aar), rain and stream gauges in the Dill catchment $\left(693 \mathrm{~km}^{2}\right)$ in central Germany.

spatial data set of the meso-scale Dill catchment in central Germany a systematic data aggregation (ten aggregation levels from $25 \mathrm{~m}$ to $2 \mathrm{~km}$ resolution) and subsequent model application using current landuse data, as well as three landuse scenarios is performed investigating the influence of data aggregation on model applicability in case of the TOPLATS model (Famiglietti and Wood, 1994). The study was motivated by the international initiative on Ensemble Model Prediction of the Effects of Landuse Change on Hydrology, organised by the Working Group on Resources Management of the University of Gießen.

\section{Material and methods}

\subsection{Study region}

The Dill catchment $\left(693 \mathrm{~km}^{2}\right)$ belongs to the Lahn-Dill low mountainous region in central Germany. It is the target catchment of the collaborative research centre SFB 299 ("Landuse options for peripheral regions") of the University of Gießen (Germany) and represents a typical peripheral region dominated by extensive agriculture and forestry. Mean annual precipitation is between $700 \mathrm{~mm}$ to $1100 \mathrm{~mm}$ and is highly correlated to the elevation which ranges between $155 \mathrm{~m}$ and $674 \mathrm{~m}$ above sea level. Average annual mean temperature is about $8^{\circ} \mathrm{C}$. The main soil types are cambisols, planosols and gleysols. For the entire catchment a data set in $25 \mathrm{~m}$ resolution is available for topography (digital elevation model), soil types, current landuse and three landuse scenarios. Two weather stations are located in the catchment providing daily data on temperature, air humidity, wind speed and global ra- diation. Stream flow is observed at four gauges, precipitation at 15 gauges (Fig. 1). All time series are available for a 20 years time period (1980-1999).

\subsection{TOPLATS model}

The TOPLATS model (TOPMODEL based atmosphere transfer scheme; Famiglietti and Wood, 1994; Peters-Lidard et al., 1997) is a multi-scale model to simulate local to regional scale catchment water and energy fluxes. It combines the local scale SVAT approach (soil vegetation atmosphere transfer scheme) to represent local scale vertical water fluxes with the catchment scale TOPMODEL approach (Beven et al., 1995) to laterally redistribute the water within a catchment. There is no lateral interaction between the local SVATs accounted for by the model. But based on the soils topographic index of the TOPMODEL approach a lateral redistribution of water is realized by adaptation of the local groundwater levels which are used as lower boundary conditions of the local SVATs. Main process descriptions of TOPLATS are summarized in Table 1. In order to reduce the calibration to a minimum, parameterisation of the TOPLATS model was carried out by deriving as many parameters as possible from standard data bases. Soil parameters were derived using the pedotransfer function of Rawls and Brakensiek (1985). Topographic parameters were calculated directly from the digital elevation model and plant parameters were taken from the PlaPaDa data base (Breuer et al., 2003). Hence, the calibration was reduced to adjusting stomatal resistances by a constant factor to meet the long-term water balance and to the adaptation of the parameters of the base flow recession curve. 
Table 1. Hydrological processes and process descriptions within the TOPLATS model.

\begin{tabular}{lll}
\hline Model part & Process & Approach \\
\hline Local SVATs & Interception & Storage approach: storage capacity is proportional to leaf area index \\
& Actual & $\begin{array}{l}\text { Reduction of potential Penman-Monteith evapotranspiration by soil } \\
\text { moisture status }\end{array}$ \\
& Infiltration & $\begin{array}{l}\text { Infiltration capacity depending on soil properties and soil water status } \\
\text { (Milly, 1986) }\end{array}$ \\
& Infiltration excess runoff & Rainfall rate minus infiltration capacity \\
& Saturation excess runoff & Contributing areas derived from TOPMODEL \\
& Percolation & Gravity driven drainage \\
& Capillary rise & Capillary rise from water table: Gardner (1958) \\
& Lower boundary & Top of capillary fringe \\
\hline TOPMODEL & Water tables & Soils-topographic index \\
& Base flow & Exponential decay function \\
\hline
\end{tabular}

Table 2. Areal proportions of landuse classes of current landuse and three different landuse scenarios in the Dill catchment provided by ProLand (values for water and urban areas remain constant).

\begin{tabular}{ccccccc}
\hline Landuse data set & Forest & Pasture & Crops & Fallow & Water & Urban \\
\hline Current landuse & $54.4 \%$ & $20.5 \%$ & $6.5 \%$ & $9.1 \%$ & $0.3 \%$ & $9.2 \%$ \\
Scenario: 0.5 ha & $56.0 \%$ & $31.8 \%$ & $2.7 \%$ & - & $0.3 \%$ & $9.2 \%$ \\
Scenario: 1.5 ha & $45.9 \%$ & $17.5 \%$ & $27.1 \%$ & - & $0.3 \%$ & $9.2 \%$ \\
Scenario: 5.0 ha & $34.0 \%$ & $20.6 \%$ & $35.9 \%$ & - & $0.3 \%$ & $9.2 \%$ \\
\hline
\end{tabular}

\subsection{Landuse scenarios}

The landuse scenarios investigated in this project are so called field size scenarios. The average field size in the Dill catchment is currently smaller than 1 ha. This is mainly a result of the traditional inheritance system where land is split between all children. This heritage system and the geomorphologic boundary conditions of the area led to the characteristic heterogeneous landscape pattern. The existing land tenure and the small field sizes currently do not support fulltime farmers. Part time farms with high machinery cost are common in the catchment. As result of the small acreages and the high machinery costs, farmers do not use any large machines. One way of increasing the farm income and supporting the utilization of larger machineries is field aggregation by land consolidation. This may lead to a change in production systems, resulting in a landuse distribution which is different compared to current situation (Weber et al., 2001).

Landuse scenarios were developed using the "ProLand model" (Fohrer et al., 2002) and provided by the Working Group on Resources Management of the University of Gießen. ProLand is an agro-economical model that predicts optimal production systems, such as intensive or extensive rangeland, suckler cow production, dairy, cropland, or forest, for a given location. It accounts for different natural, technical, economic and political premises and assumes that farmers act to optimize their land rent. The field size scenarios were provided by ProLand assuming different boundary conditions for farming practices, for example different field size allocations. ProLand predicts economic variables and provides spatially explicit landuse maps. These maps serve as input for the scenario analysis. ProLand differentiates between several pasture and crop production systems, as well as mixed forest. Based on different target field sizes of 0.5, 1.5 and 5.0 hectares, three different landuse maps are provided in $25 \mathrm{~m}$ resolution which can be used for scenario analysis. Statistics of landuse scenarios compared to the current conditions are given by Table 2 .

\subsection{Data aggregation}

The available grids of soil types, topography, landuse and landuse scenarios ( $25 \mathrm{~m}$ resolution) were systematically aggregated stepwise to create grid-based data sets of increasing grid size $(50 \mathrm{~m}, 75 \mathrm{~m}, 100 \mathrm{~m}, 150 \mathrm{~m}, 200 \mathrm{~m}, 300 \mathrm{~m}, 500 \mathrm{~m}$, $1 \mathrm{~km}, 2 \mathrm{~km}$ ). The aggregation of the digital elevation model was carried out by calculating the simple averages of the pixels to be aggregated. Concerning soils and landuse, the data sets were aggregated with respect to the majority of the pixels to be aggregated. The most frequent value was allocated 


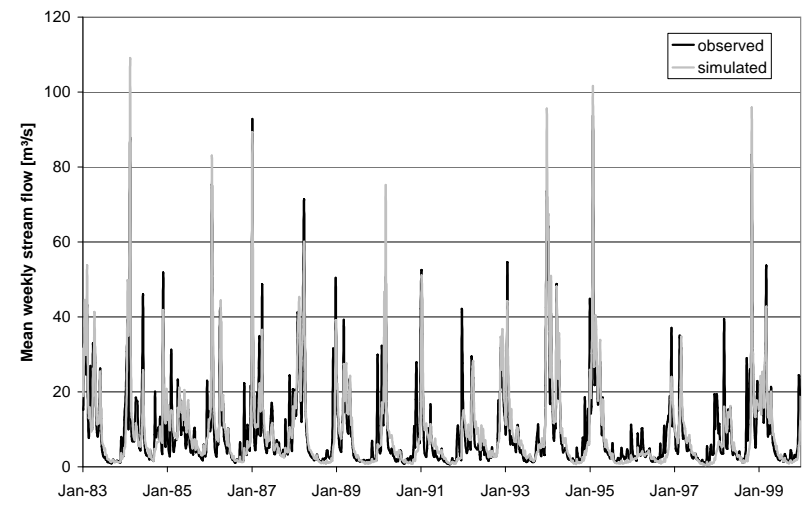

Fig. 2. Comparison of observed versus simulated stream flow of the Dill catchment in weekly resolution.

to the aggregated pixel. If there was no unambiguous majority the surrounding pixels were included into the allocation procedure (Bormann, 2006).

\section{Grid size dependent model results}

For the current landuse conditions, TOPLATS was calibrated for the whole Dill catchment using the data of the years 1983-1989, validation period was 1990-1999, and the years 1980-1982 were used as a spin up period. The accuracy of the simulation (Fig. 2) is satisfactory considering that TOPLATS was calibrated only with minimum effort. Quality measures for the validation period are only slightly worse than for the calibration period. While for daily discharges the model efficiency (Nash and Suttcliffe, 1970) is of moderate quality ( 0.65 for calibration, 0.61 for validation), the model efficiencies and coefficients of determination increase for longer time intervals (weeks, months) to values greater than 0.8. The mean deviation in annual discharge between observations and simulations is about $\pm 5.9 \%$ for the calibration and $\pm 12.0 \%$ for the validation period.

For the simulation of the three subcatchments a recalibration was carried only for the maximum baseflow parameter ("baseflow at basin saturation"). The simulation results for the Dietzhölze $\left(81 \mathrm{~km}^{2}\right)$ and on the upper Dill $\left(63 \mathrm{~km}^{2}\right)$ are quite good while the results for the Aar catchment $\left(134 \mathrm{~km}^{2}\right)$ are of a moderate quality. Model efficiencies for daily discharges range from 0.59 (Aar) to 0.73 (upper Dill, Diezhölze) for the calibration period, and from 0.52 (Aar) to 0.69 (upper Dill, Diezhölze) for the validation period. They increase with increasing time intervals to values of $0.76-0.85$ (weeks) and 0.82-0.90 (months).

In order to analyse the effect of input data resolution on simulation results for all grid sizes derived from the original data sets (10 grids ranging from $25 \mathrm{~m}$ to $2 \mathrm{~km}$ resolution), continuous water balance simulations for 20 years were performed. Exemplary results of the grid size dependent total stream flows (sums of simulated surface runoff and base

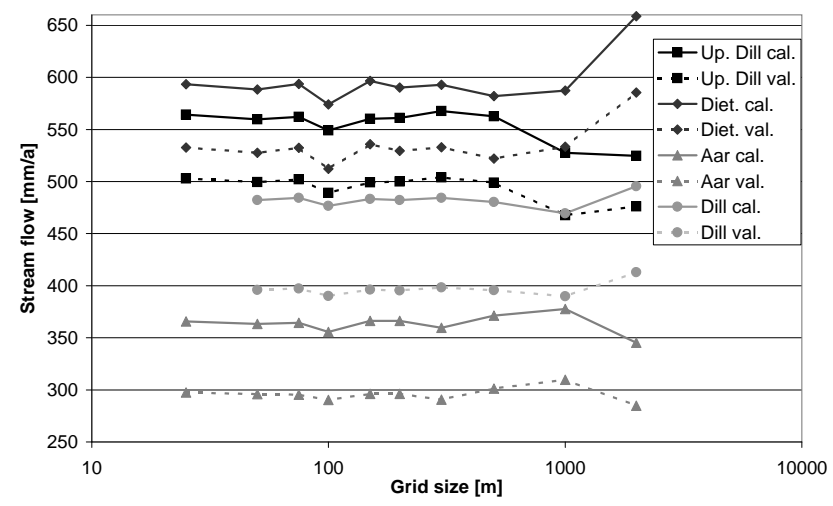

Fig. 3. Dependence of total stream flow (surface runoff + base flow) on grid sizes for the Dill basin and its three subcatchments (Up. Dill $=$ Upper Dill, Diet. $=$ Dietzhölze $)$. Calibration and validation periods (cal., val.) are analysed separately.

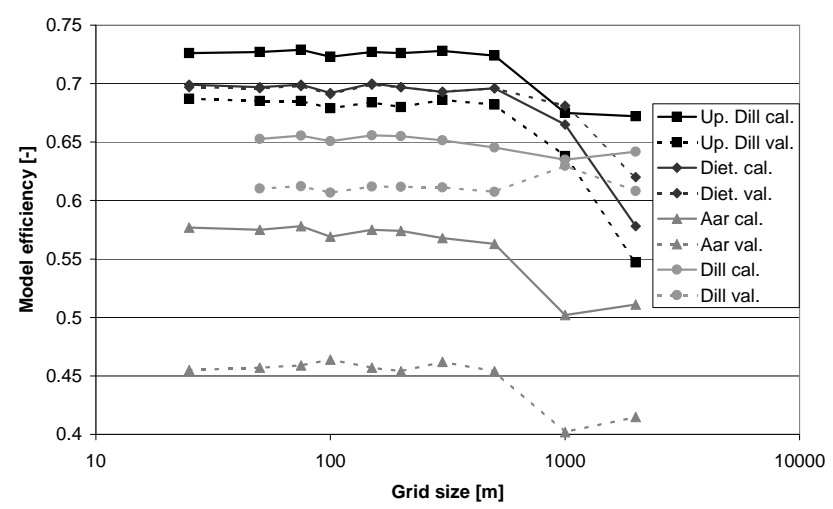

Fig. 4. Dependence of model efficiencies on grid sizes for the Dill basin and its three subcatchments (Up. Dill = Upper Dill, Diet. = Dietzhölze). Calibration and validation periods (cal., val.) are analysed separately.

flow) are shown in Fig. 3. Up to a grid size of $500 \mathrm{~m}$ the simulated water fluxes remain almost constant except slight differences at the grid size of $100 \mathrm{~m}$, which can be explained by differences in landuse composition at the $100 \mathrm{~m}$ aggregation level (Bormann, 2006). At a grid size of $500 \mathrm{~m}$ the differences slightly increase, and from $1 \mathrm{~km}$ grid size onwards the simulation results get significantly different. Differences with respect to simulations based on high resolutions increase. The same systematics of these results can be found for all main simulated water fluxes (evapotranspiration, surface runoff, base flow, stream flow) in all investigated catchments, and results are also similar for the calibration and the validation period.

A very similar structure of results also shows the analysis concerning the dependence of the model efficiencies on grid size (Fig. 4). As expected from the simulated water balances they remain constant up to an aggregation level of $300 \mathrm{~m}$ to $500 \mathrm{~m}$ grid size. Model efficiencies for the $1 \mathrm{~km}$ and the $2 \mathrm{~km}$ 
(a)

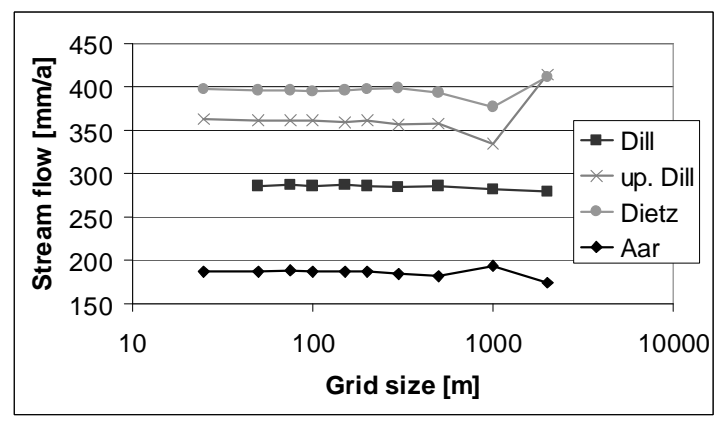

(c)

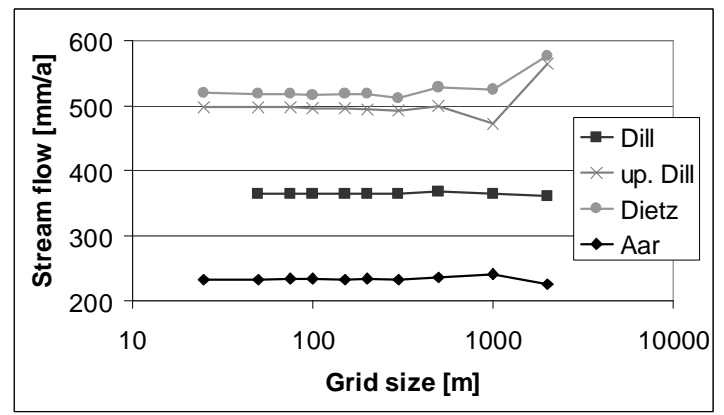

(e)

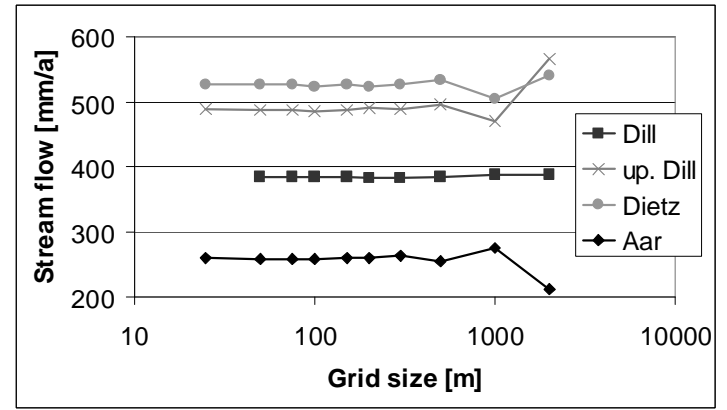

(b)

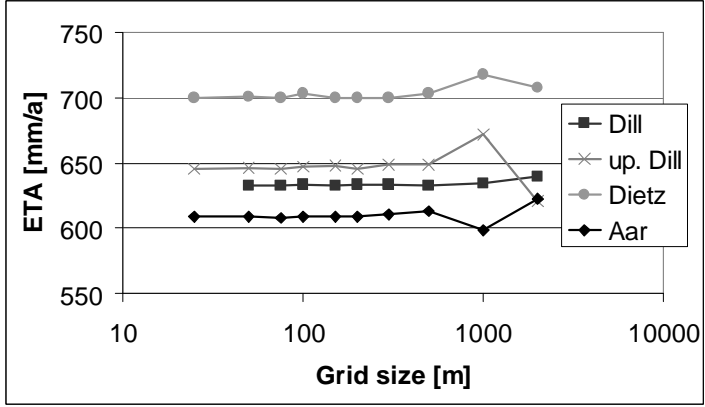

(d)

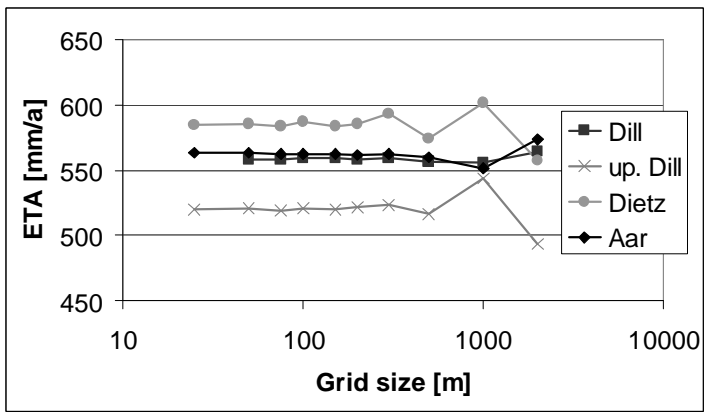

(f)

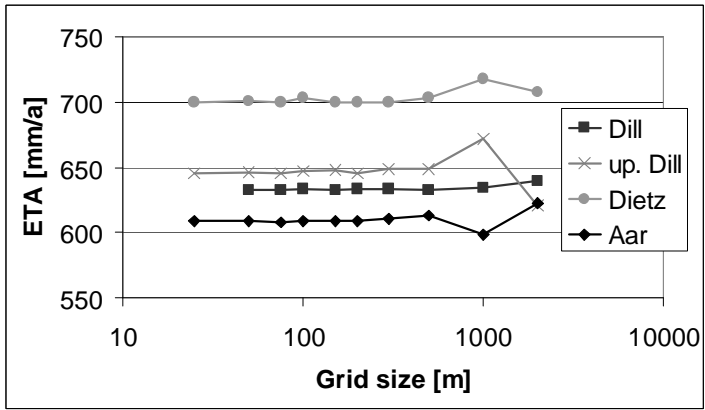

Fig. 5. Dependence of simulated water balances on grid size for scenarios for the Dill catchment - scenarios with target field size of 0.5 ha (a), 1.5 ha (b) and 5.0 ha (c); ETA = actual evapotranspiration.

grids are significantly lower. For these grid sizes a significant and systematic decrease of the quality measures (model efficiency, coefficient of determination) is observed. A detailed analysis of the dependence of simulation results and model quality measures on grid size, as well as on correlations to input data is given by Bormann (2006).

Analysing the simulated water balances of three landuse scenarios available for the Dill catchment, the same systematics of the effect of aggregation on simulated water fluxes is observed (Fig. 5). For the Dill catchment as a whole and for all investigated subcatchments the annual water fluxes remain almost constant up to a grid size of $300 \mathrm{~m}$ except the simulated actual evapotranspiration of the 1.5 ha (target field size of 1.5 ha) scenario for the Dietzhölze (Fig. 5b) which shows a clear deviation at the $300 \mathrm{~m}$ level. As observed for the current landuse, slight deviations occur at the $100 \mathrm{~m}$ level due to aggregation of landuse data, slight deviations also occur at the $500 \mathrm{~m}$ level and significant deviations are observed for $1 \mathrm{~km}$ and $2 \mathrm{~km}$ grid sizes. While the deviation of the simulation results based on large grid cells compared to small grid sizes can be positive or negative, the absolute values of the deviations are high for all investigated water flows (50$100 \mathrm{~mm} / \mathrm{a}$ ) and especially for the subcatchments. 
(a)

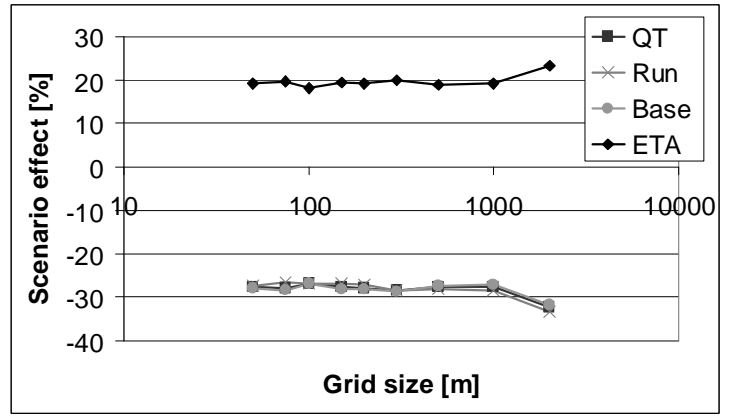

(c)

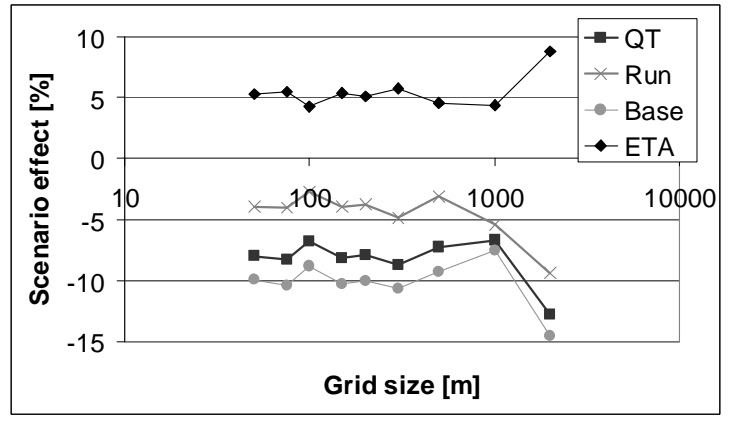

(e)

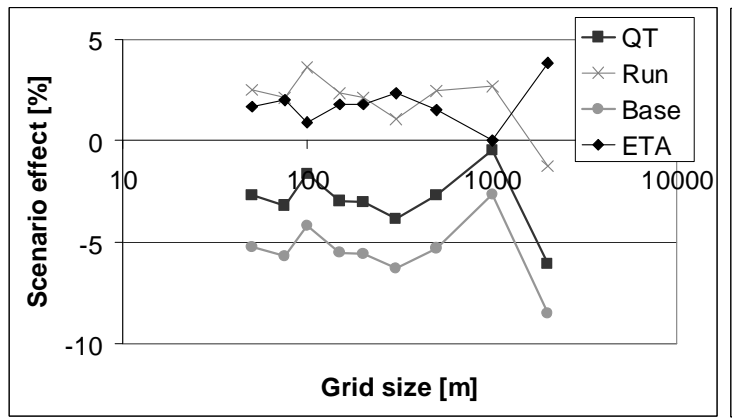

(b)

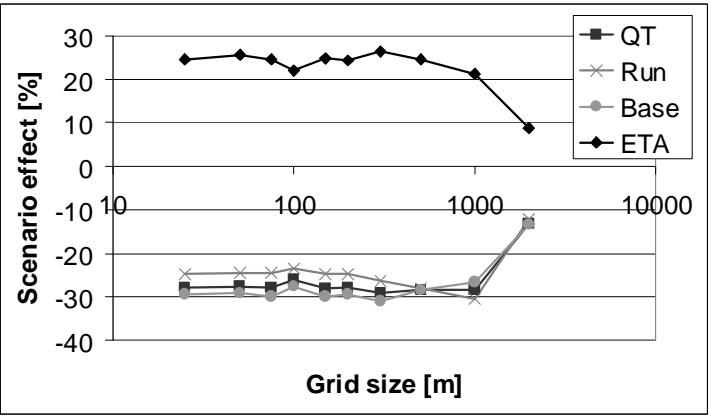

(d)

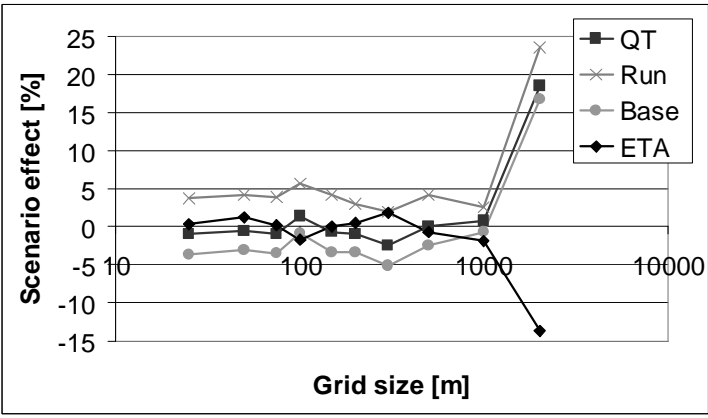

(f)

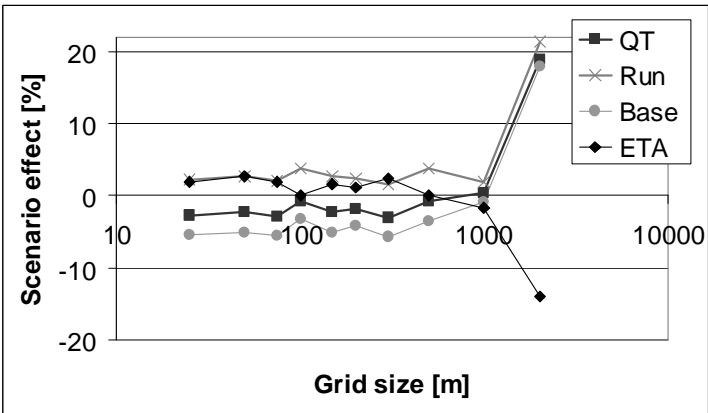

Fig. 6. Dependence of relative scenario effects (= ((current - scenario)/current $))$ on grid size for the Dill catchment (a, b, c) and the upper Dill subcatchment (d, e, f): scenarios with target field sizes of 0.5 ha (a, d), 1.5 ha (b, e) and 5.0 ha $(\mathrm{c}, \mathrm{f})$; QT $=$ stream flow, Run $=$ surface runoff, Base = base flow, ETA = actual evapotranspiration.

\section{Grid size dependent scenario effects}

Focusing on the differences between simulation results based on current landuse conditions and the simulations based on the three different landuse scenarios provided by ProLand (Table 2), a partly different picture is obtained as relative changes of the fluxes due to data aggregation are focused on. The definition of the scenario effects with respect to the water flows (e.g. evapotranspiration, surface runoff, base flow, stream flow) is given by:

scenario effect $=\frac{\text { current-scenario }}{\text { current }}$ where scenario $=$ simulated water flow $[\mathrm{mm} / \mathrm{a}]$ based on landuse scenario at a distinct grid size, and current $=$ simulated water flow $[\mathrm{mm} / \mathrm{a}]$ based on current landuse at the same grid size.

Different effects are identified for the scenarios. While the 0.5 ha scenario (target field size of $0.5 \mathrm{ha}$ ) reacts relatively robust on increasing grid size (Figs. 6a, d, 7a, and d), the 1.5 ha and the 5.0 ha scenarios (target field size of 1.5 ha and 5.0 ha, respectively) show higher sensitivities to aggregation of input data grids. The robust behaviour of the 0.5 ha scenario can be explained by the considerable changes in water flows induced by the scenario. Changes in the annual water flows by 
(a)

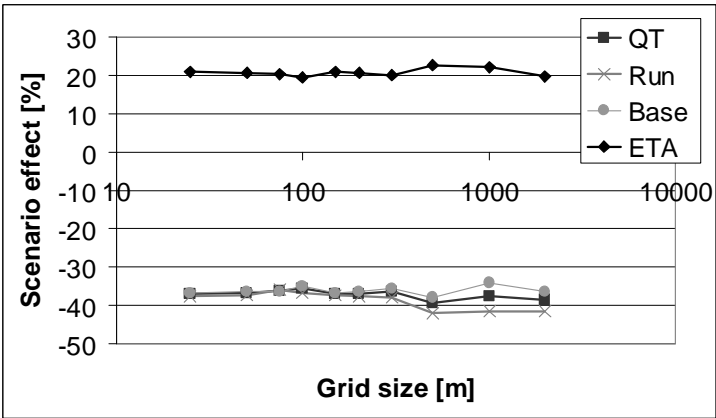

(c)

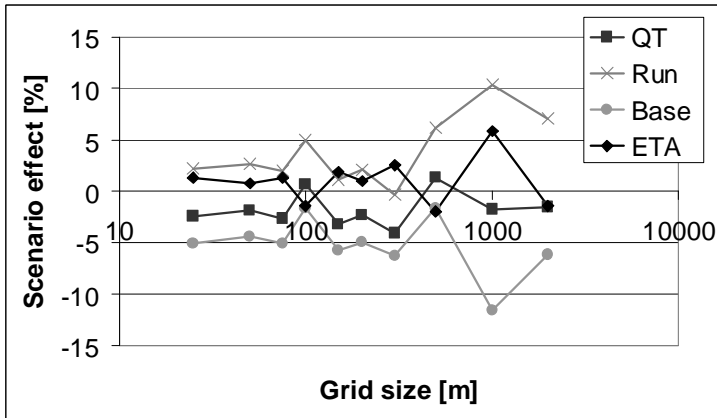

(e)

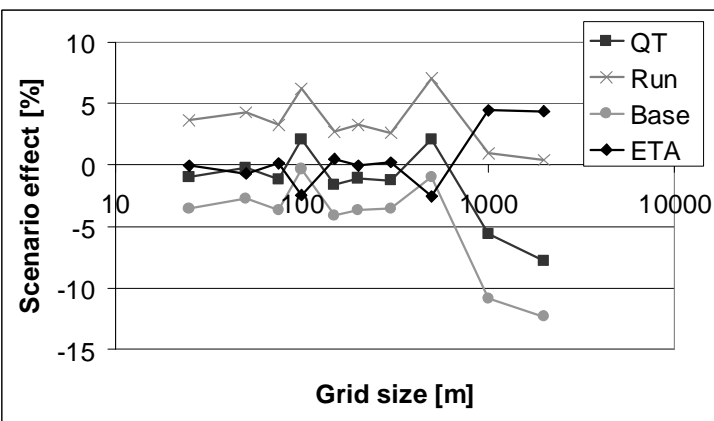

(b)

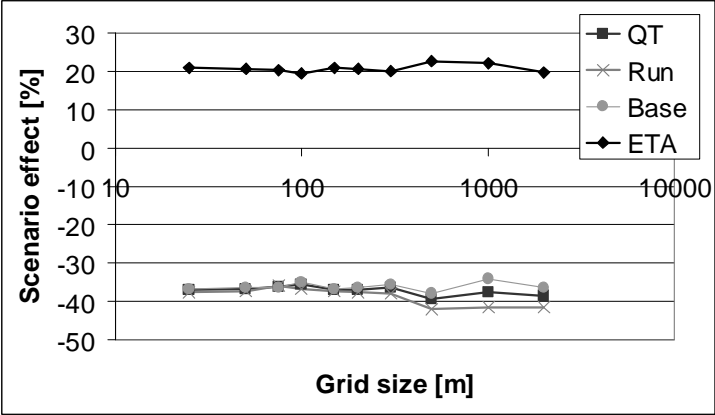

(d)

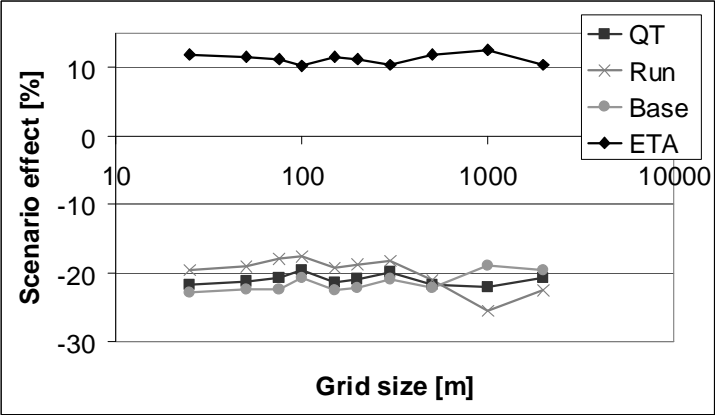

(f)

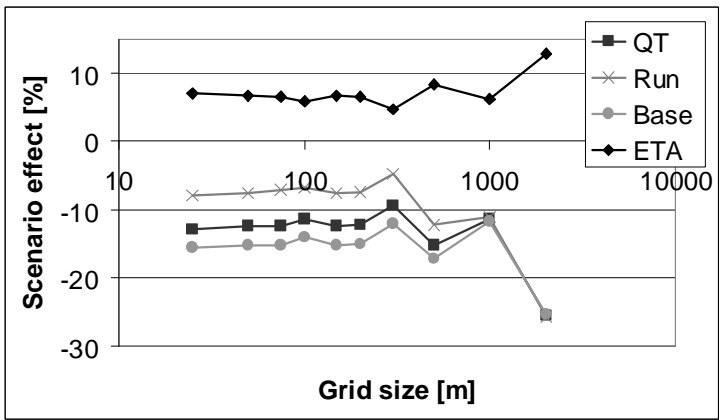

Fig. 7. Dependence of relative scenario effects (= ((current - scenario)/current)) on grid size for the Dietzhölze (a, b, c) and the Aar subcatchment (d, e, f): scenarios with target field sizes of 0.5 ha (a,d), 1.5 ha (b, e) and 5.0 ha (c, f); QT = stream flow, Run = surface runoff, Base $=$ base flow, ETA $=$ actual evapotranspiration.

$\pm 20-30 \%$ mask differences between the aggregation levels in the order of a few percent. This is in contrast to the $1.5 \mathrm{ha}$ and 5.0 ha scenarios which cause changes in annual water flows of about $\pm 5 \%$ except for the Aar subcatchment. Hence uncertainties due to aggregation in the order of a few percent can have a significant impact in simulated scenario effects. This leads to the problem that differences caused by aggregation can lead to a change in the magnitude of the scenario effect (e.g. for the Dill and the Aar rivers, Figs. 6c, 7f) as well as even lead to a change in the direction of change caused by landuse scenarios (e.g. for the Dietzhölze river compared to current situation, Figs. 7b, c). Nevertheless, although the sensitivity of scenario effects on aggregation seems to be higher then the sensitivity of water balances, the effects of aggregation on scenario results are similar for smaller grid sizes (between $25 \mathrm{~m}$ and $200 \mathrm{~m}$ except the $100 \mathrm{~m}$ level). For increased grid sizes significant deviations can be expected.

\section{Conclusions}

This study indicates that an aggregation of spatial input data for the calculation of regional water balances using TOPLATS type models does not lead to significant 
deviations in simulation results data up to a grid size of $300 \mathrm{~m}$. Between a grid size of $300 \mathrm{~m}$ and $500 \mathrm{~m}$ a slight to partly significant information loss leads to affected simulation results. Applying the model on a grid size of $1 \mathrm{~km}$ and more causes significant errors in the computed water balance.

Changes in scenario effects react more sensitive to aggregation of data than the simulated water balance terms. Up to a grid size of $200 \mathrm{~m}$ the deviations compared to the smallest grid sizes remain small except aggregation levels where aggregation changed the statistics of landuse composition significantly. The increased sensitivity of simulated scenario effects compared to the water balance terms can have two reasons. It firstly can be explained by the partly limited magnitude of scenario effects compared to the uncertainty induced by the aggregation process. Secondly aggregation effects in current state data and scenario data sets add up and therefore intensify model sensitivity.

Thus due to the existence of model sensitivity to data resolution, scenario studies in general should be carried out in combination with uncertainty studies. Focusing on scenario effects, the magnitude of the simulated changes, which depends on the flow process accounted for, should be set in relation to the sensitivity of the model due to model and data resolution. This can be accomplished for example by performing a comprehensive uncertainty analysis and analysing the signal-to-noise ratio between scenario effects and model uncertainty suggested by Bormann (2005).

Acknowledgements. The author thanks the Deutsche Forschungsgemeinschaft for funding the collaborative research centre SFB 299 on "landuse options for peripheral regions" and the organisers of the Freudenstadt-Workshop on "Großskalige Modellierung in der Hydrologie" for the excellent organisation.

Edited by: R. Barthel, J. Götzinger, G. Hartmann, J. Jagelke, V. Rojanschi, and J. Wolf

Reviewed by: anonymous referees

\section{References}

Beven, K. J., Lamb, R., Quinn, P. F., Romanowicz, R., and Freer, J.: TOPMODEL, in: Computer Models of Watershed Hydrology, edited by: Singh, V. P., Water Resources Publications, 627-668, 1995.

Bormann, H.: Impact of spatial data resolution on simulated catchment water balances and model performance of the multi-scale TOPLATS model, Hydrol. Earth Syst. Sci., 10, 165-179, 2006, http://www.hydrol-earth-syst-sci.net/10/165/2006/.

Bormann, H.: Evaluation of hydrological models for scenario analyses: Signal-to-noise-ratio between scenario effects and model uncertainty. Adv. Geosci., 5, 43-48, 2005, http://www.adv-geosci.net/5/43/2005/.

Breuer, L., Eckhardt, K., and Frede, H.-G.: Plant parameter values for models in temperate climates, Ecol. Model., 169, 237-293, 2003.

Famiglietti, J. S. and Wood, E. F.: Multiscale modelling of spatially variable water and energy balance processes, Water Resour. Res., 30(11), 3061-3078, 1994.

Farajalla, N. and Vieux, B.: Capturing the essential variability in distributed hydrological modeling: infiltration parameters, Hydrol. Process. 9, 55-68, 1995.

Fohrer, N., Möller, D., and Steiner, N.: An interdisciplinary modelling approach to evaluate the effects of landuse change, Phys. Chem. Earth, 27, 655-662, 2002.

Gardner, W. R.: Some steady-state solutions of the unsaturated moisture flow equation with application to evaporation from a water table, Soil Sci., 85, 228-239, 1958.

Kuo, W.-L., Steenhuis, T. S., McCulloch, C. E., Mohler, C. L., Weinstein, D. A., DeGloria, S. D., and Swaney, D. P.: Effect of grid size on runoff and soil moisture for a variable-source-area hydrology model, Water Resour. Res. 35(11), 3419-3428, 1999.

Milly, P. C. D.: An event based simulation model of moisture and energy fluxes at a bare soil surface, Water Resour. Res., 22, 1680-1692, 1986.

Nash, J. E. and Suttcliffe, J. V.: River flow forecasting through conceptual models, Part I. A discussion of principles, J. Hydrol., 10(3), 282-290, 1970.

Pelgrum, H.: Spatial aggregation of land surface characteristics: impact of resolution of remote sensing data on land surface modelling, Dissertation, Wageningen, 151p., 2000.

Peters-Lidard, C .D., Zion, M. S., and Wood, E. F.: A soilvegetation-atmosphere transfer scheme for modeling spatially variable water and energy balance processes, J. Geophys. Res., 102(D4), 4303-4324, 1997.

Rawls, W. J. and Brakensiek, D. L.: Prediction of soil water properties for hydrological modelling, in: Proceedings of the symposium watershed management in the eighties, edited by: Jones, E. and Ward, T. J., Denver, 293-299, 1985.

Weber, A., Fohrer, N., and Möller, D.: Long-term landuse changes in a mesoscale watershed due to socioeconomic factors - effects on landscape and functions, Ecol. Model., 140, 125-140, 2001. 